\title{
PROSPECTIVE ANALYSIS OF PRISCRIPTION PATTERN OF ANTIMICROBIAL THERAPY FOR URINARY TRACT INFECTIONS IN PREGNANT FEMALE PATIENT
}

\author{
Shikha Pal ${ }^{1 *}$, Dr. Vandana Sharma ${ }^{2}$, Dr. Mukesh Sharma ${ }^{2}$, Samridhi Khandelwal ${ }^{1}$, Ramesh \\ Pareek $^{3}$, Shailendra Tripathi ${ }^{3}$ \\ ${ }^{1}$ Research Scholar, Arya College of Pharmacy, Jaipur \\ ${ }^{2}$ Professor, Arya College of Pharmacy, Jaipur \\ ${ }^{3}$ Asso. Professor, Arya Collge of pharmacy, Jaipur
}

\section{Conflicts of Interest: Nil}

\section{Corresponding author: Shikha Pal}

DOI https://doi.org/10.32553/ijpba.v9i1.177

\begin{abstract}
Pregnancy is a state of relative immunocompromise. This immunocompromise may be another cause for the increased frequency of UTIs seen in pregnancy. UTIs are one of the most common medical complications of pregnancy. Urinary tract infections (UTI) in pregnancy are a large and under-emphasized risk factor for pregnancy morbidity and adverse birth outcomes in low- and middle-income country. A prospective, single centric, observational and descriptive type hospital based study was conducted at the Gynecology Department of a tertiary care hospital for a period of 9 months. This prospective analysis comprises the prevalence of UTI in 53 pregnant female patients with study of their antibiotic prescription pattern. this present prospective study shows that the prevalence rate of urinary tract infection in pregnancy is $26.5 \%$.(53 UTI cases out of screened 200 patients) Controversially, many literature reviewed showed that in pregnant women's UTI incidence can be as high as 8 to $20 \%$. Present study indicates the incidence of UTI in pregnancy in relation to gestation period shows that max. UTI patients are from second Trimester (55\%) in comparison to first trimester (28\%). Least rate of UTI incidence was in Third trimester (17\%) due to clinical supervision of pregnant females from starting of gestation. Observation indicates incidence of UTI in relation to age groups under three gestation periods, max. UTI patients were under age group 21 to 30 years of all gestation periods. In first trimester, Second Trimester and third trimester there were $68 \%, 62 \%$ and $56 \%$ respectively UTI patients were under age group 21-30 years. This prevalence was due to physiological changes that occur majorly in second trimester. Incidence of UTI pregnant patients under age group $<20$ years was more in both $1^{\text {st }}$ and $3^{\text {rd }}$ trimester than under age group $>30$ years. These findings indicate that no relationship exists between age and incidence of UTI in pregnancy.

Urinary Tract Infections are confirmed on the basis of bacteriuria present. Urinary tract infections are generally uncomplicated in non pregnant females but becomes complicated in pregnancy specially when left untreated. Present study showed incidence of uncomplicated urithritis and cystitis $(65 \%)$ and No complicated UTI cases (pyelonephritis). Gestation distribution of uncomplicated UTI patients showed that max. urithritis(38\%) was in

Present study shows the frequently isolated organism in UTI in pregnancy include species of Enterobacteriaceae especially Escherichia coli and others citrobactor and proteus. Klebsiella was the second $(22 \%)$ most isolated organism. Cephalosporin's with more than $90 \%$ general susceptibility than fluoroquinolones (<90\%). Average general susceptibility was found with Ampicillin and sulphonamides. fluoroquinolones was also alternative choices. All antibiotic prescription was based on antibiotic sensitivity to culture organism. Present study shows max UTI patients of $1^{\text {st }}$ trimester received Nitrofurantoin (47\%) as a monotherapy. Due to Antibiotic sensitivity to cultural organism, ciphalosporins and fluoroquinolones was also prescribed as monotherapy. Only single UTI pregnant patient shows sensitivity to cotrimoxazole in first trimester. Cotrimoxazole was prescribed with folic acid supplement. As a safe nonteratogenic drug nitrofurantoin was prescribed to max patients with others drugs in combination. Phenazopyridine an urinary analgesic also prescribed in max. number in combination with nitrofurantoin.
\end{abstract}


Data analysis of observation of $2^{\text {nd }}$ trimester showed that higher percent distribution of patients were received Nitrofurantoin with other drug combinations. Max. no of patients $(75 \%)$ received Nitrofurantoin with phenazopyridine in comparision to other urinary antibiotics. Patients with Vit.B12 deficiency were also receiving Nitofurantoin with folic acid supplement. Only single Hypertensive pregnant received Methyldopa with ciphalosporins. Only single case of gestational diabetes received nitrofurantoin with glibenclamide with safer indication. Nitrofurantoin was again highly prescribed urinary antibiotic drug with other drug combination.

Present study revealed in $3^{\text {rd }}$ trimester fluoroquinolones were better treatment options with other drugs combination. All pregnant female patients with or without Comorbid conditions received fluoroquinolones.

Keywords: fluoroquinolones, Nitrofurantoin

\section{INTRODUCTION}

A urinary tract infection (UTI) is an infection in any part of urinary system including kidneys, ureters, bladder and urethra. UTI is defined as significant bacteriuria in the setting of symptoms of cystitis or pyelonephritis. The urinary tract can be divided into the upper urinary tract and the lower urinary tract. The upper urinary tract consists of the kidneys and the ureters, and the lower urinary tract consists of the bladder and the urethra. Most infections involve the lower urinary tract - the bladder and the urethra. Urinary tract infection is an extremely common condition that occurs in both male and female of all the ages. The prevalence and incidence of UTI is higher in women than in men, due to several clinical factors including anatomic differences, hormonal effects and behavioral patterns. Pregnancy is a state of relative immunocompromise. This immunocompromise may be another cause for the increased frequency of UTIs seen in pregnancy. UTIs are one of the most common medical complications of pregnancy. Urinary tract infections (UTI) in pregnancy are a large and under-emphasized risk factor for pregnancy morbidity and adverse birth outcomes in low- and middle-income country (LMIC) settings. Increased incidence of UTI during pregnancy is due to the morphological and the physiological changes that take Place in the genitourinary tract during pregnancy.

Urinary tract infections (UTIs) are frequently encountered in pregnant women. Pyelonephritis is the most common serious medical condition seen in pregnancy. Thus, it is crucial for providers of obstetric care to be knowledgeable about normal findings of the urinary tract, evaluation of abnormalities, and treatment of disease. Fortunately, UTIs in pregnancy are most often easily.

Pregnancy causes numerous hormonal and mechanical changes in the body.Changes of the urinary tract and immunologic changes of pregnancy predispose women to urinary tract infection. Physiologic changes of the urinary tract include dilation of the ureter and renal calyces; this occurs due to progesterone-related smooth muscle relaxation and ureteral compression from the gravid uterus. Ureteral dilation may be marked. Decreased bladder capacity commonly results in urinary frequency.

Beginning in the $6^{\text {th }}$ week, with peak incidence during $22^{\text {nd }}-24^{\text {th }}$ weeks of gestation, $90 \%$ of the pregnant women develop ureteric dilatation thereby increasing the risk of urinary stasis and vesicoureteric reflux. ${ }^{4}$ In addition, glycosuria and aminoaciduria during pregnancy provide an excellent culture medium for bacteria in areas of urinary stasis. These changes along with already short urethra and difficulty with hygiene due to the distended pregnant belly increase the frequency of UTI in pregnant women.

\section{CLASSIFICATION ON THE BASIS OF ANATOMIC SITE OF INVOLVEMENT}

Each type of UTI has more-specific signs and symptoms, depending on which part of urinary tract is affected. They are -

\section{A. UPPER URINARY TRACT INFECTIONS B. LOWER URINARY TRACT INFECTIONS}

\section{A. Upper urinary tract infections: Kidney and ureter}

Infections of the upper urinary tract include pyelonephritis. When Kidneys are affected called acute pyelonephritis.

\section{B. Lower urinary tract infections: Bladder and urethra}

Infections of the lower urinary tract include cystitis, urethritis. When bladders are affected called cystitis and when urethra are affected called urethritis.

\section{STUDY PROCEDURE}

\subsection{Study design}

A prospective, single centric, observational and descriptive type hospital based study, will be conducted at the Gynecology Department of a tertiary care hospital for a period of 9 months from January 25, 2020 - 0ct 31, 2020. The study will be initiated after with due permission from Head of the 
Clinical Research Department, Heart \& General Hospital and from the Institutional Ethical Committee approval from the hospital. About 200 pregnant Females will be screened for UTI's during the study from the time of admission.

\section{Study Site:}

Gynecology Department, Heart \& General Hospital, Jaipur

\section{Sample size:}

Pregnant Female patients visiting the Medicine OPD for consultation.

\section{Study population:}

Pregnant Female patients diagnosed with Urinary Tract Infections who conformed to the specified Inclusion and Exclusion Criteria will be enrolled for this study.

\section{Inclusion criteria}

- Pregnant females with Urinary Tract Infections (OPD patients)

- Pregnant Female patients $>18$ years of age group

\section{Exclusion criteria}

- Pregnant females without Urinary Tract Infections (OPD patients)

- Hospitalized/Inpatient females admitted for Delivery

- Pregnant Female patients $<18$ years of age group

- Pregnant female patients with other Noscomial infections

\section{Source of data}

Patient Case Report Form (Patient demographics, past medical and medication history, laboratory Findings, Prescription).

\section{Data collection:}

The data will be collected from the individual patient in a structured Performa i.e. Case Report Form.

\section{Study population/ Research subjects:}

A total of 100 pregnant female patients are included in this study are diagnosed with urinary tract infections and who are matched for Inclusion criteria consecutively attending the outpatient care clinic of the Heart \& General Hospital, established through consultation with treating physicians are reviewed.

They are over 18 years of age and underwent treatment with Antimicrobial therapy. All study subjects gave written and oral informed consent as they were recruited at the Gyane department. Subjects are randomly selected in this study who meets the Inclusion criteria. Patients with Exclusion criteria as per study protocol are not included in this study.

\subsection{Study Procedure:}

A CRF was prepared to record the following information of the pregnant female patients visited to Out Patients Department OPD.

Prescription Pattern: According to WHO core prescribing indicators---

- Average drugs prescribed

- Generic Name Wise Drug Prescribed

- Antibiotics Prescribed

- Injections Prescribed

- Drugs prescribed ( Listed in Essential Drug List India-2019)

\section{Socio-Demographic Profile:}

- Name, Age, Sex and Education of Patient

- Occupation and Family income (to classify under socio-economic group)

- Locality and Address of Patient

Above mentioned data and physicians prescribed prescription pattern of antibiotics of each outdoor pregnant female patients were collected electronically on predesigned Case Report form.

Pregnant female patients with urinary tract infection receiving antibiotics alone or in combination.

\subsection{Data Analysis and Statistical Method:}

Descriptive statistics will be used to summarize Patients demographics and survey responses. Percentage of data will be calculated by using Microsoft Excel sheet.

A suitable statistical test will be used to compare the rate of antibiotics prescribed as per standard guideline and not as per guidelines. All testing will be done at a significance level of 0.05 .

\section{RESULTS}

A prospective, single centric, observational and descriptive type hospital based study, was conducted at the Gynecology Department of a tertiary care hospital for a period of 9 months from January 25, 2020 - 0ct 31, 2020. The study will be initiated after with due permission from Head of the Clinical Research Department, Heart \& General Hospital and from the Institutional Ethical Committee approval 
from the hospital. About 200 pregnant Females will be screened for UTI's during the study from the time of admission.
3.1 Prevalence of UTI in screened pregnant female patients

Out of total screened pregnant females, 53 pregnant females were found to have UTI. Show in Table.1

Table : 1 Prevalence of UTI in pregnancy

\begin{tabular}{|l|l|l|}
\hline Total number of pregnancy cases & Patients with UTI in Pregnancy & Percent \\
\hline 200 & 53 & $26.5 \%$ \\
\hline
\end{tabular}

\section{Chart 1:Prevalence of UTI in pregnancy}

$\square$ Total number of Pregnancy Cases

$\triangle$ Patients with UTI in Pregnancy

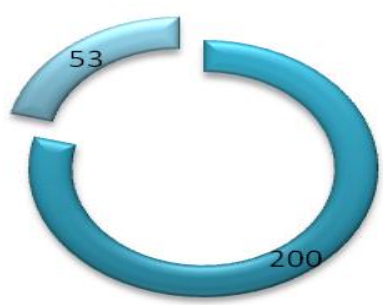

3.2 Patient Details According to Gestation Period:

Table 2, showing, distribution of pregnant female patients according to their gestation period, out of total 53 pregnant female patients with UTI.

Table 2: - Distribution of Patients According to Gestation Period

\begin{tabular}{|l|l|l|}
\hline Gestation Period & No. of Patients & $\begin{array}{l}\text { Percent Distribution } \\
(\%)\end{array}$ \\
\hline First Trimester & 15 & 28.30 \\
\hline Second Trimester & 29 & 54.71 \\
\hline Third Trimester & 09 & 16.98 \\
\hline Total & 53 & 100 \\
\hline
\end{tabular}

\section{Chart 2: Percent Distribution of Patients According to Gestation Period(\%)}

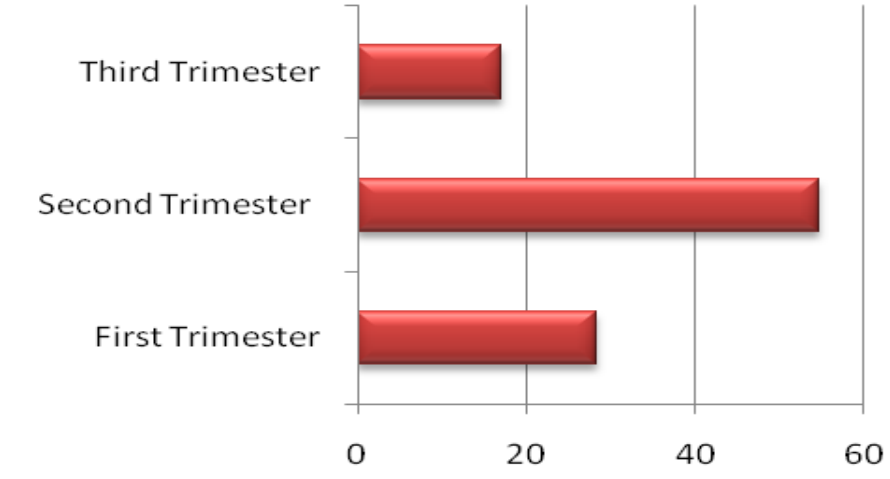




\subsection{Demographic Detail of Patients}

\subsubsection{Age Distribution of patients according to their Gestation Period}

\subsubsection{For First Trimester}

Table 6.3.1.1, showing, percent distribution of pregnant female patients according to their Age in first Trimester period, out of total 15 pregnant female patients with UTI.

\section{First Trimester}

Table 3. For First Trimester Age Distribution of patients

\begin{tabular}{|l|l|l|}
\hline Age & No. of Patients & Percent $(\%)$ \\
\hline$<20$ years & 03 & 20 \\
\hline $21-30$ years & 10 & 66.66 \\
\hline 30 years & 02 & 13.33 \\
\hline Total & 15 & $100 \%$ \\
\hline
\end{tabular}

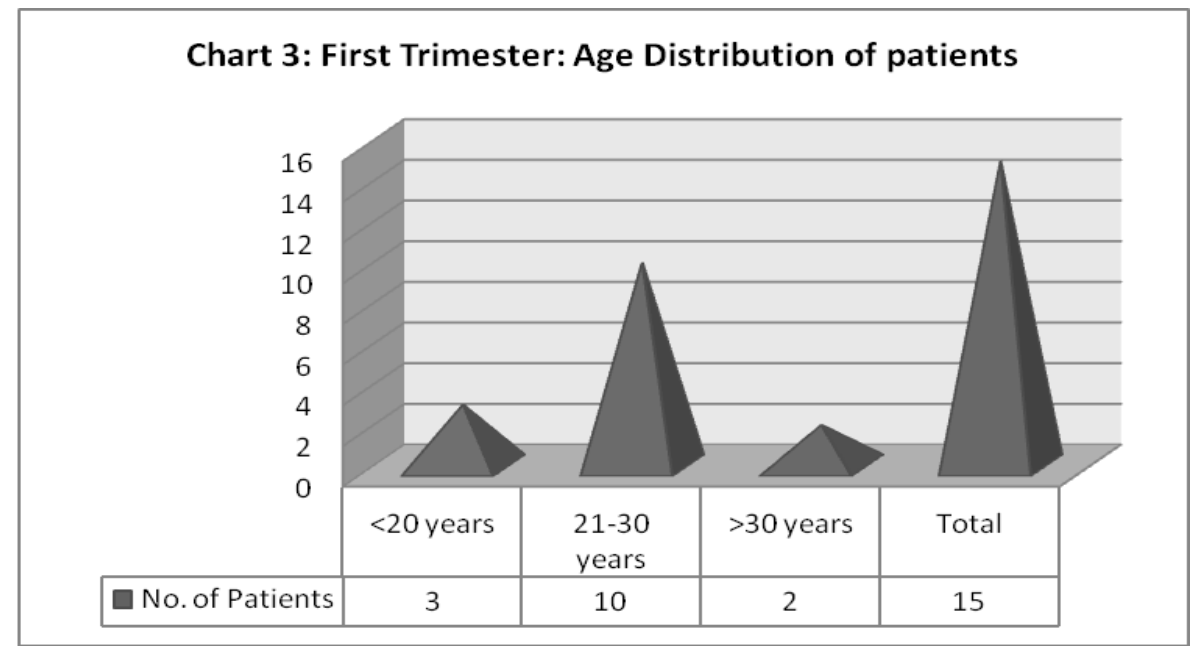

\subsubsection{For Second Trimester}

Table 4, showing, percent distribution of pregnant female patients according to their Age in second Trimester period, out of total 29 pregnant female patients with UTI.

\begin{tabular}{|c|c|c|}
\hline \multicolumn{3}{|c|}{ Second Trimester } \\
\hline Age & No. of Patients & Percent (\%) \\
\hline$<20$ years & 07 & 24.13 \\
\hline 21-30 years & 18 & 62.06 \\
\hline$>30$ years & 04 & 13.79 \\
\hline Total & 29 & $100 \%$ \\
\hline
\end{tabular}

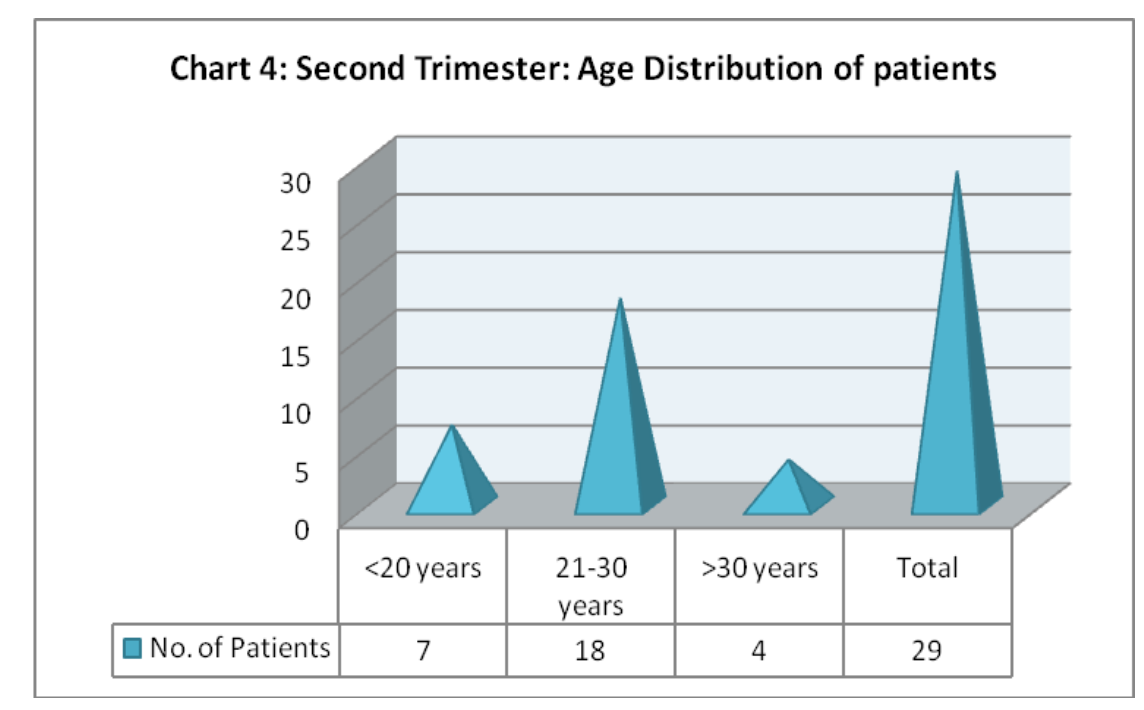




\subsubsection{For Third Trimester}

Table 5, showing, percent distribution of pregnant female patients according to their Age in Third Trimester period, out of total 09 pregnant female patients with UTI.

Table 5. For Third Trimester Age Distribution of patients

\begin{tabular}{|l|l|l|}
\hline Third Trimester & No. of Patients & Percent $(\%)$ \\
\hline Age & 03 & 33.33 \\
\hline$<20$ years & 05 & 55.55 \\
\hline $21-30$ years & 01 & 11.11 \\
\hline 30 years & 09 & $100 \%$ \\
\hline Total & & \\
\hline
\end{tabular}

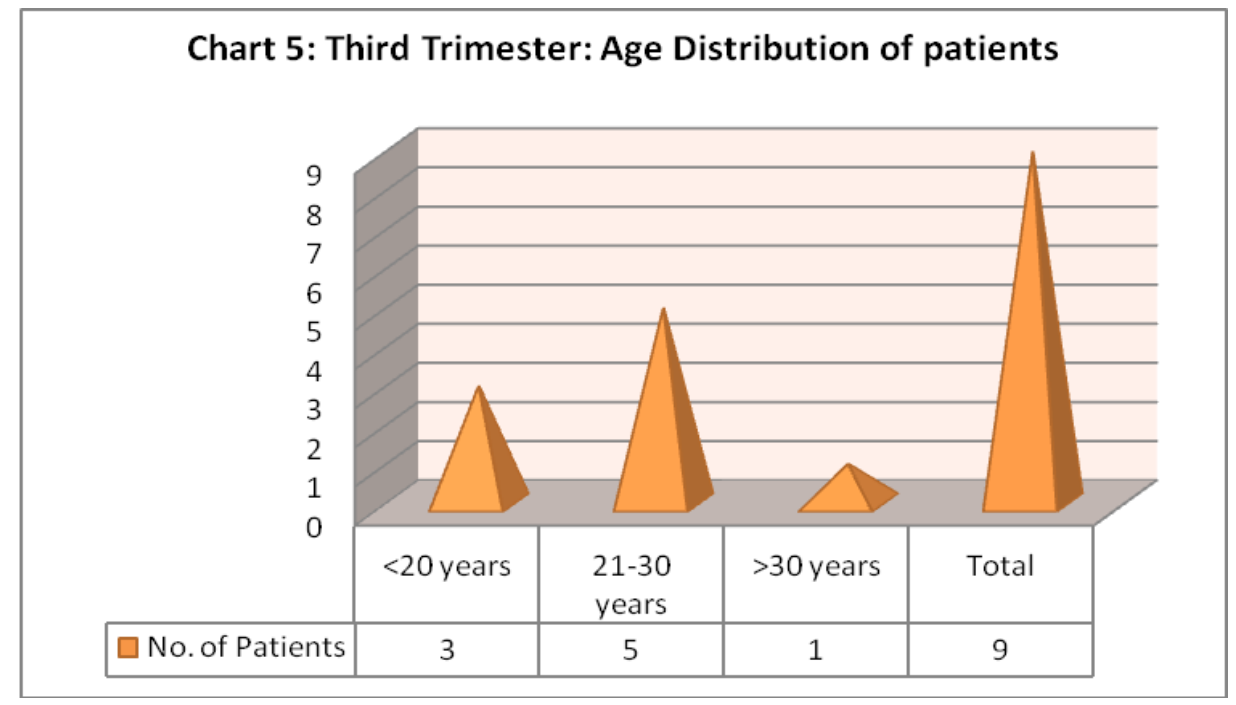

\subsubsection{Distribution of patients according to their Locality}

Table 6, showing, distribution of pregnant female patients according to their locality in gestation period, out of total 53 pregnant female patients with UTI.

Table 6. Patient Distribution According to Locality

\begin{tabular}{|l|l|l|l|}
\hline Number of Patients & \multicolumn{2}{l|}{} \\
\hline Locality & First Trimester & Second Trimester & Third Trimester \\
\hline Rural & 06 & 16 & 05 \\
\hline Urban & 09 & 13 & 04 \\
\hline Total & 15 & 29 & 09 \\
\hline
\end{tabular}

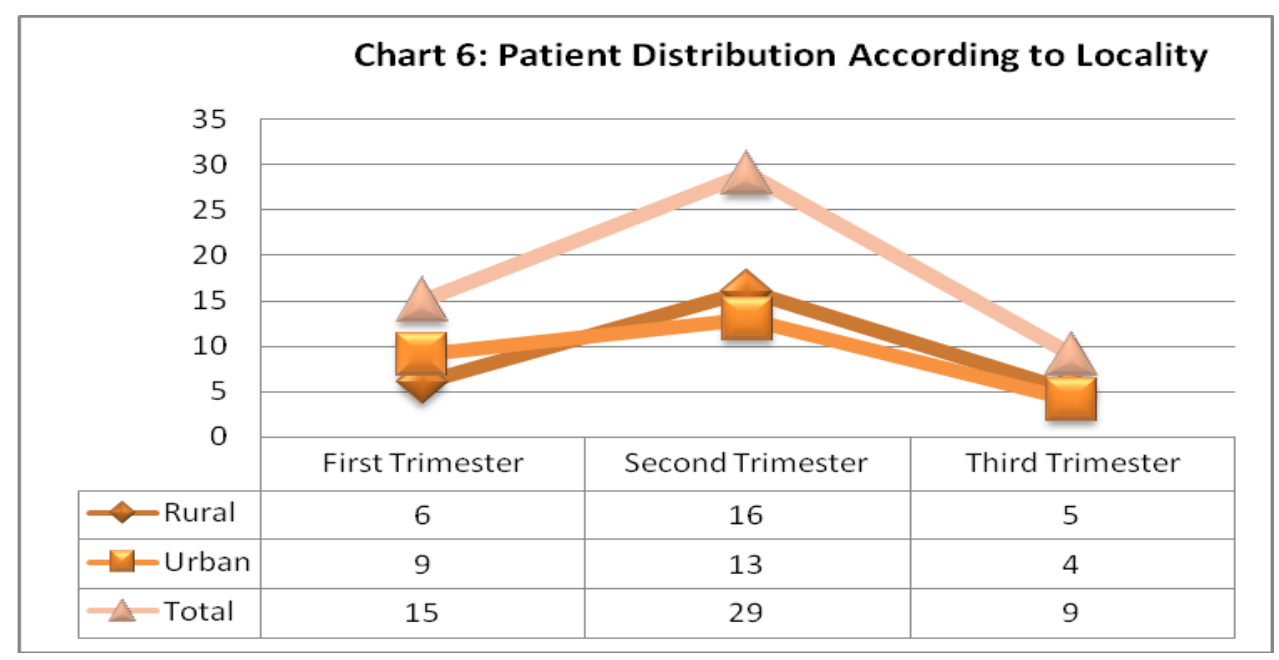




\subsubsection{Distribution of patients according to their Socioeconomic Status}

Table 7. Socioeconomic Distribution of patients

\begin{tabular}{|l|l|l|}
\hline Socioeconomic Status & Number of Patients & Percent (\%) Distribution \\
\hline Upper & 03 & 5.66 \\
\hline Upper Middle & 03 & 5.66 \\
\hline Lower Middle & 18 & 33.96 \\
\hline Lower & 29 & 54.71 \\
\hline Total & $\mathbf{5 3}$ & $100 \%$ \\
\hline
\end{tabular}

Chart 7: Socioeconomic Distribution of patients

- Upper $\quad$ Upper Middle $\square$ Lower Middle $\square$ Lower

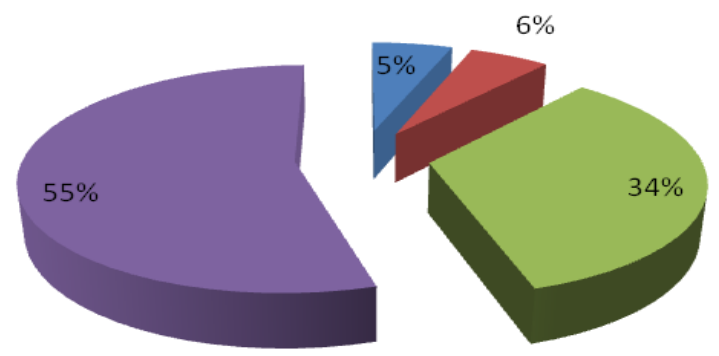

3.4 Clinical Observation Detail of Patients

3.4.1 Bacteriuria in Pregnant female patients with UTI

Table 8. Bacteriuria in Pregnant female patients with UTI

\begin{tabular}{|l|l|l|}
\hline Bacteriuria & Number of Patients & Percent (\%) Distribution \\
\hline Symptomatic Bacteriuria & 19 & 35.84 \\
\hline Asymptomatic Bacteriuria & $\mathbf{3 4}$ & $\mathbf{6 4 . 1 5}$ \\
\hline Total & $\mathbf{5 3}$ & $\mathbf{1 0 0 \%}$ \\
\hline
\end{tabular}

Chart 8: Bacteriuria in Pregnant female patients with UTI

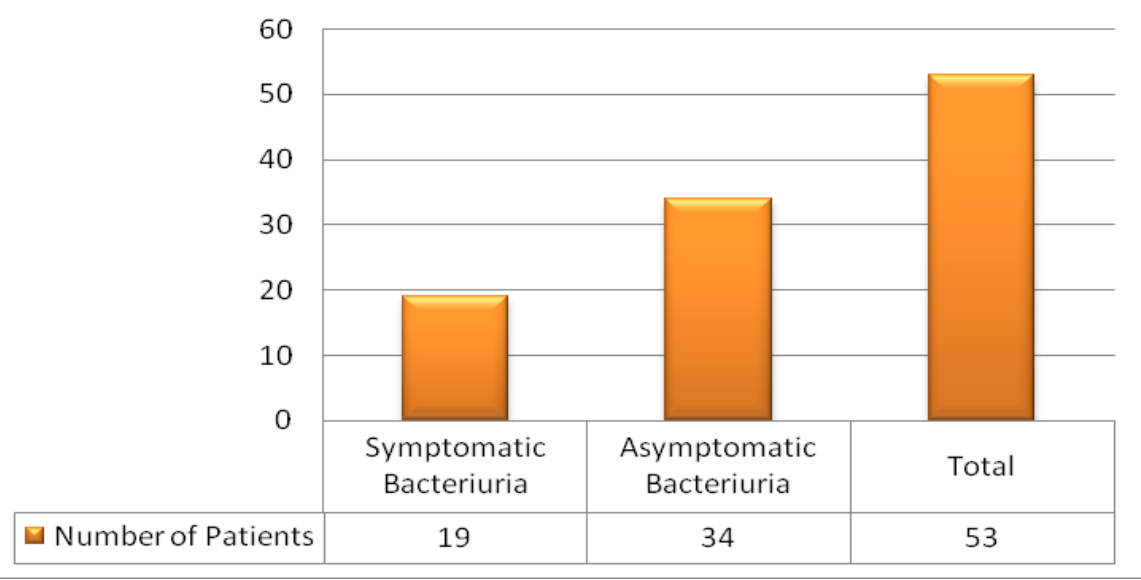

Table 9. Asymptomatic Bacteriuria in Pregnant female patients with UTI according to Gestation Period.

\begin{tabular}{|l|l|l|}
\hline Asymptomatic Bacteriuria & \multicolumn{2}{l|}{} \\
\hline Gestation Period & Number of Patients & Percent (\%) Distribution \\
\hline First Trimester & 09 & 26.47 \\
\hline Second Trimester & 20 & 58.82 \\
\hline Third Trimester & $\mathbf{0 5}$ & $\mathbf{1 4 . 7 0}$ \\
\hline Total & $\mathbf{3 4}$ & $\mathbf{1 0 0 \%}$ \\
\hline
\end{tabular}




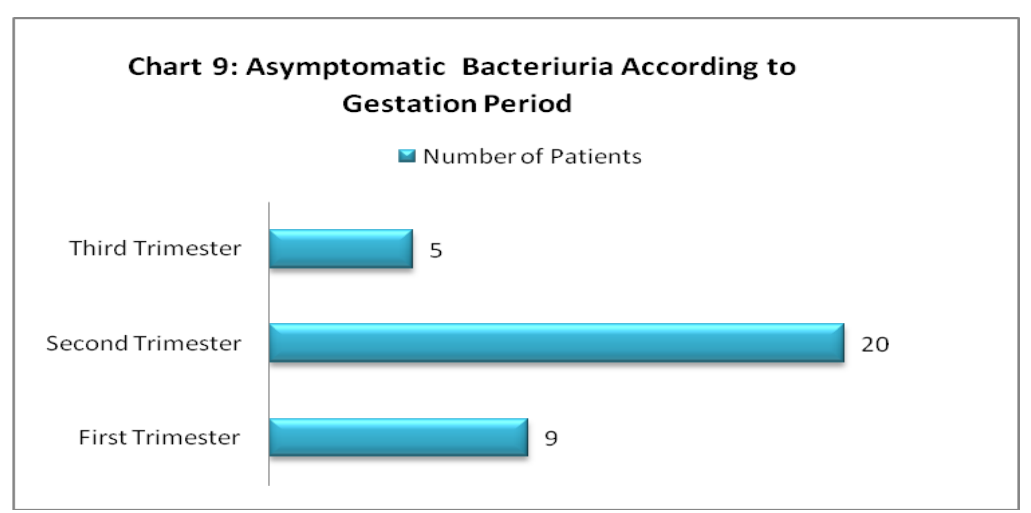

Table 10. Symptomatic Bacteriuria in Pregnant female patients with UTI according to Gestation Period.

\begin{tabular}{|l|l|l|}
\hline Symptomatic Bacteriuria & \multicolumn{2}{l|}{} \\
\hline Gestation Period & Number of Patients & Percent (\%) Distribution \\
\hline First Trimester & 06 & 31.57 \\
\hline Second Trimester & 09 & 47.36 \\
\hline Third Trimester & 04 & 21.05 \\
\hline Total & 19 & $100 \%$ \\
\hline
\end{tabular}

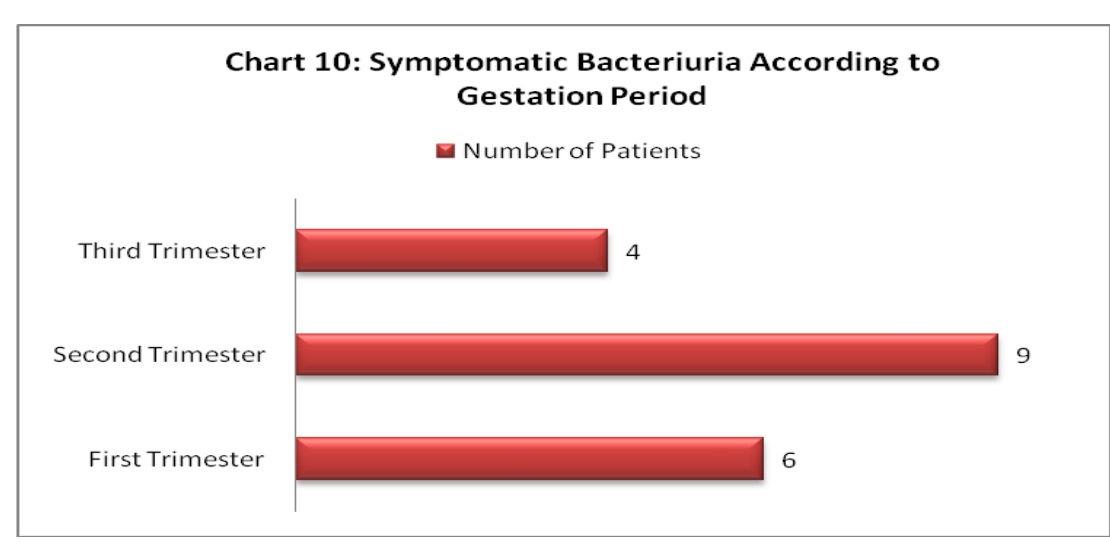

\subsubsection{Distribution of pregnant female patients with UTI according to complication}

Table 11. Distribution of Patients according to Complications

\begin{tabular}{|l|l|l|}
\hline Complications & Number of Patients & Percent (\%) Distribution \\
\hline Complicated UTI (Pyelonephritis) & 0 & 00 \\
\hline $\begin{array}{l}\text { Uncomplicated UTI } \\
\text { Cystitis, Urithritis) }\end{array}$ & 19 & 64.15 \\
\hline Total & 19 & $100 \%$ \\
\hline
\end{tabular}

Chart 11: Number of Patients According to UTI Complications

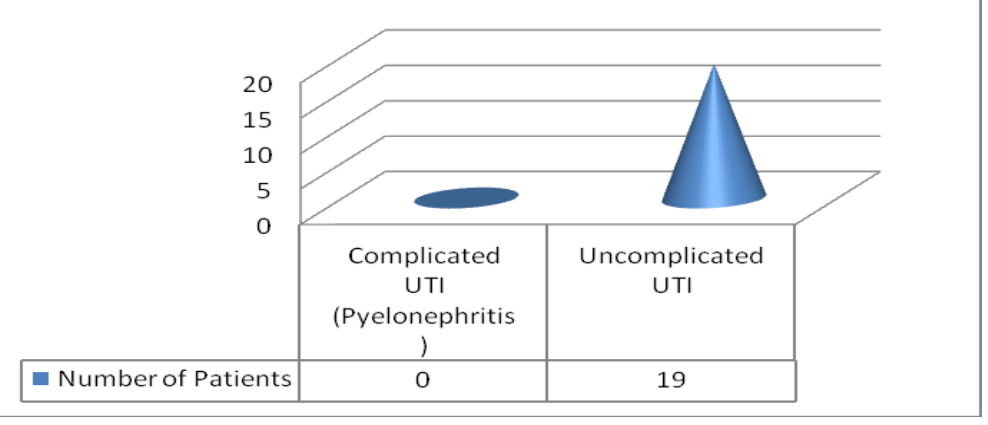


Table 12. Distribution of Uncomplicated UTI Patients according to Gestation Period.

\begin{tabular}{|l|l|l|}
\hline Uncomplicated UTI Patients (Urithritis) & \multicolumn{2}{l|}{} \\
\hline Gestation Period & Number of Patients & Percent (\%) Distribution \\
\hline First Trimester & 05 & 38.46 \\
\hline Second Trimester & 04 & 30.76 \\
\hline Third Trimester & 04 & 30.76 \\
\hline Total & 13 & $100 \%$ \\
\hline
\end{tabular}

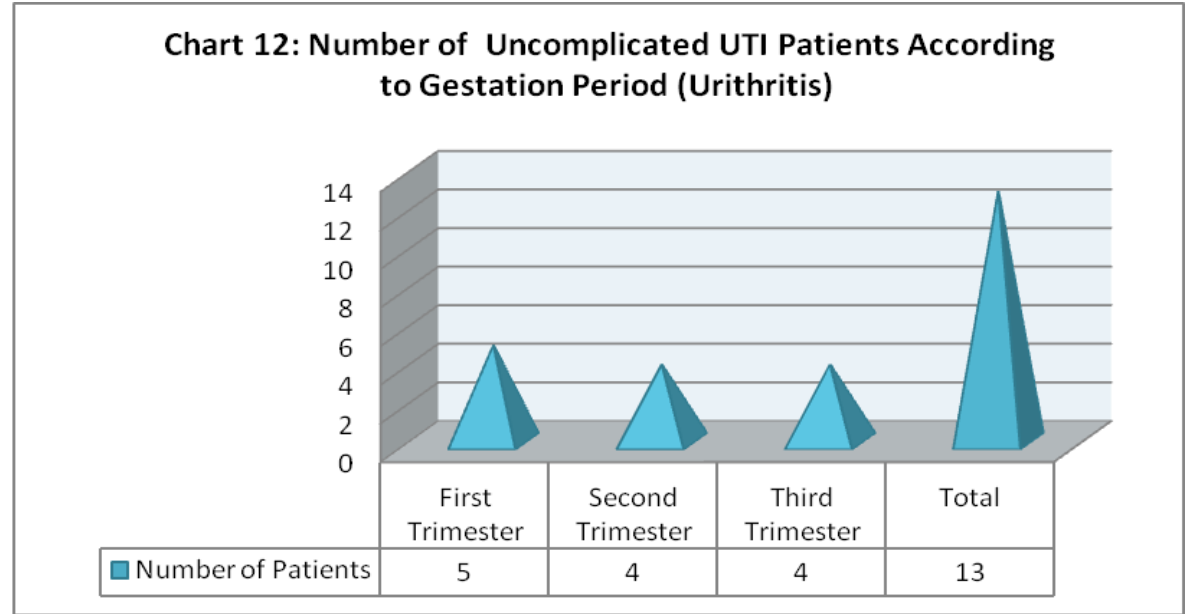

Table 13. Distribution of Uncomplicated UTI Patients according to Gestation Period.

\begin{tabular}{|l|l|l|}
\hline Uncomplicated UTI Patients (Cystitis) & \multicolumn{2}{l|}{} \\
\hline Gestation Period & Number of Patients & Percent (\%) Distribution \\
\hline First Trimester & 01 & 16.66 \\
\hline Second Trimester & 05 & 83.33 \\
\hline Third Trimester & 00 & 00 \\
\hline Total & 06 & $100 \%$ \\
\hline
\end{tabular}

Chart 13:Number of Uncomplicated Patients According to Gestation Period(Cystitis)

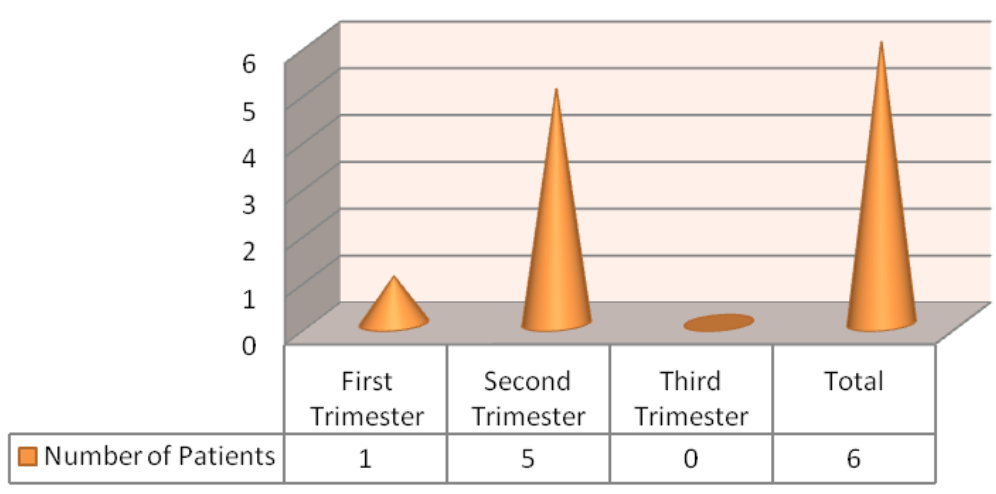

3.4.3 Distribution of pregnant female patients with UTI according to Recurrent Infections 
Table 14. Distribution of Recurrent UTI Infections according to Gestation Period.

\begin{tabular}{|l|l|l|}
\hline Recurrent UTI Infection Patients & Number of Patients & Percent (\%) Distribution \\
\hline Gestation Period & 01 & 16.66 \\
\hline First Trimester & 04 & $\mathbf{8 0 . 0 0}$ \\
\hline Second Trimester & 00 & 00 \\
\hline Third Trimester & 05 & $100 \%$ \\
\hline Total & &
\end{tabular}

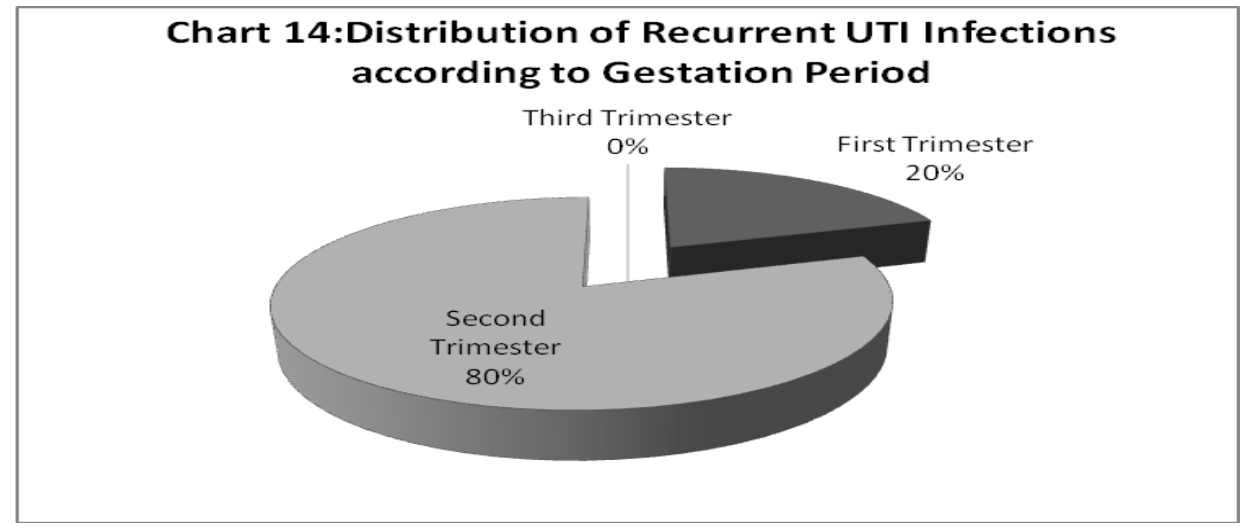

3.4.4 Isolated organism in pregnant female patients with UTI

Table 15. Isolated organism in pregnant female patients with UTI

\begin{tabular}{|l|l|l|}
\hline Isolated Organism & Number of Patients & Percent (\%) Distribution \\
\hline E.Coli & 36 & 67.92 \\
\hline Klebsiella & 12 & 22.64 \\
\hline Citrobactor & 3 & 5.66 \\
\hline Proteus & 2 & 3.77 \\
\hline Total & 53 & $100 \%$ \\
\hline
\end{tabular}

Chart 15: Isolated organism in pregnant female patients with UTI

E.Coli $\square$ Klebsiella $\square$ Citrobactor $\square$ Proteus

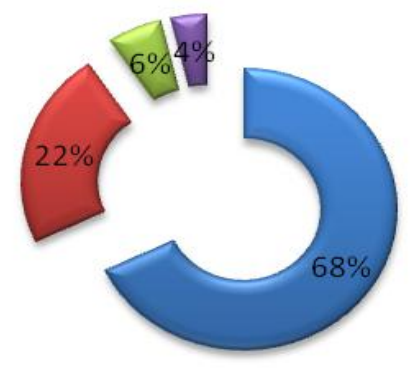

3.4.5 Antibiotic Sensitivity Pattern of 53 Isolates 
Table 16. Antibiotic Sensitivity Pattern of 53 Isolates

\begin{tabular}{|l|l|lll|l|ll|}
\hline Isolated & Total & Sensitive to & all Resistant to \\
Organism & Patients & Antibiotics & to & Resistant to & Antibiotics & \\
\hline E.Coli & 36 & 07 & 23 & 06 \\
\hline Klebsiella & 12 & 02 & 08 & 02 \\
\hline Citrobactor & 3 & 01 & 01 & 01 \\
\hline Proteus & 2 & 01 & 01 & 01 \\
\hline Total & 53 & & & \\
\hline
\end{tabular}

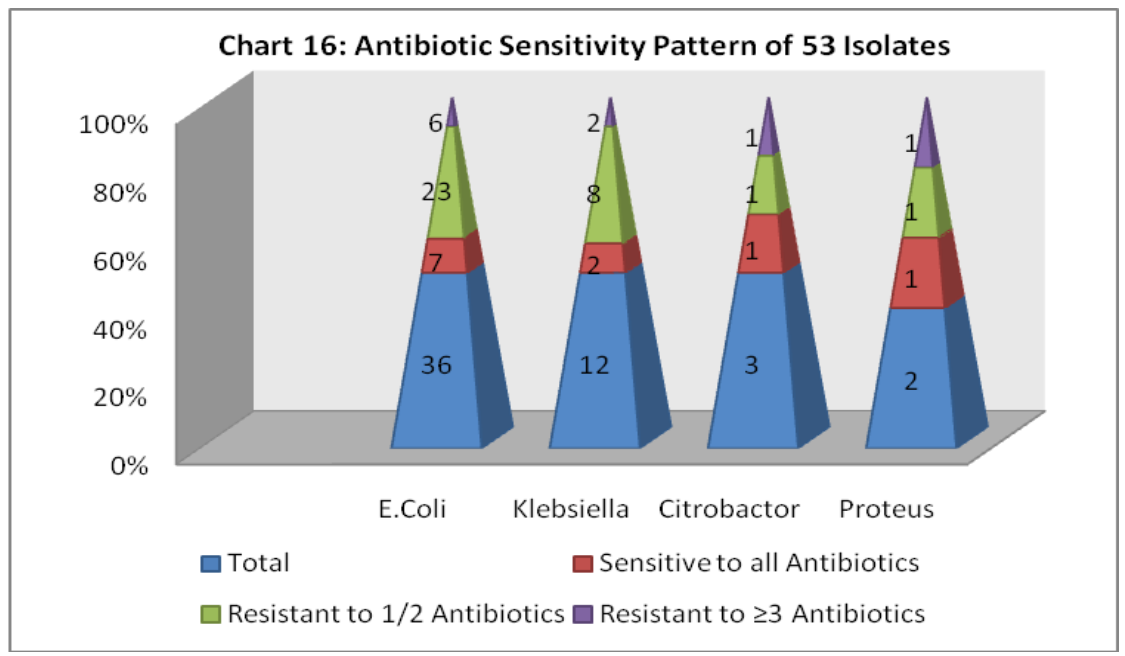

\subsubsection{General Antibiotic Susceptibility for 53 Isolates}

To the study the effectiveness of the antibiotics against the isolated organism thirteen antibiotics were used for the susceptibility study against the isolated organism.

Table 17. General Antibiotic Sensitivity Pattern of 53 Isolates

\begin{tabular}{|l|l|l|}
\hline S.No. & Antibiotic Used & Percentage of susceptibility \\
\hline 1 & Amoxicillin & $100 \%$ \\
\hline 2 & Ampicillin & $67 \%$ \\
\hline 4 & Amikacin & $100 \%$ \\
\hline 5 & Nitrofurantoin & $89 \%$ \\
\hline 6 & Nalidixic acid & $50 \%$ \\
\hline 7 & Ciprofloxacin & $80 \%$ \\
\hline 8 & Norfloxacin & $81 \%$ \\
\hline 9 & Levofloxacin & $80 \%$ \\
\hline 10 & Cotrimoxazole & $71 \%$ \\
\hline 11 & Cefpodoxime & $92 \%$ \\
\hline 12 & Cefalexin & $90 \%$ \\
\hline 13 & Ceftriaxone & $96 \%$ \\
\hline
\end{tabular}




\subsubsection{Patients distribution according to comorbidity}

Table 18. UTI Female Pregnant Patients with Comorbid Conditions

\begin{tabular}{|l|l|l|l|}
\hline Comorbid Conditions & $\begin{array}{l}\text { No. of Patients First } \\
\text { Trimester }\end{array}$ & $\begin{array}{l}\text { of Patients } \\
\text { Trimester }\end{array}$ & $\begin{array}{l}\text { Second No. of Patients Third } \\
\text { Trimester }\end{array}$ \\
\hline Anaemia & 07 & 15 & 02 \\
\hline Hypertension & 04 & 02 & 03 \\
\hline Diabetes Mellitus & 00 & 01 & 00 \\
\hline Thyroid Disorders & 00 & 00 & 00 \\
\hline
\end{tabular}

Chart 17: UTI Female Pregnant Patients with Comorbid Conditions
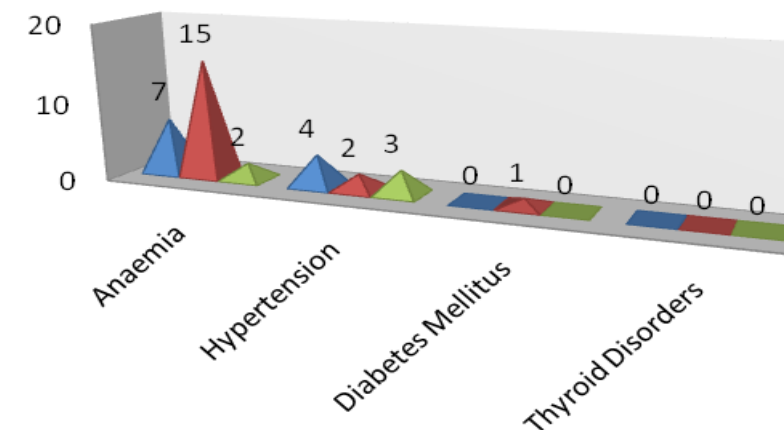

$\square$ No. of Patients First Trimester $\square$ No. of Patients Second Trimester

$\square$ No. of Patients Third Trimester

\subsection{Prescription Pattern Details}

Table 19. Antibiotic Prescription prescribed for Pregnant Female Patients with UTI in First Trimester as per Antibiotic Sensitivity

\begin{tabular}{|l|l|l|}
\hline Antibiotic Prescribed & No. of Patients First Trimester & $(\%)$ Percent Distribution \\
\hline Nitrofurantoin & 07 & 46.66 \\
\hline Ampicillin & 02 & 13.33 \\
\hline Amoxicillin & 02 & 13.33 \\
\hline Cotrimoxazole & 01 & 0.66 \\
\hline Cefalexin & 02 & 13.33 \\
\hline Total & 15 & $100 \%$ \\
\hline
\end{tabular}

Chart 18: Antibiotic Prescribed in First Trimester

$\square$ No. of Patients First Trimester

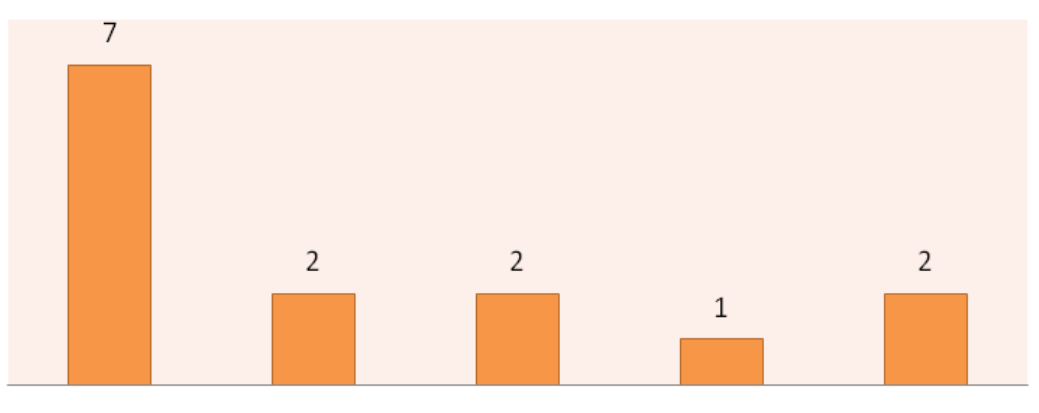

Nitrofurantoin Ampicillin Amoxicillin Cotrimoxazole Cefalexin 
Table 20. Antibiotic Prescription prescribed for Pregnant Female Patients with UTI in Second Trimester as per Antibiotic Sensitivity

\begin{tabular}{|l|l|l|}
\hline Antibiotic Prescribed & No. of Patients Second Trimester & $(\%)$ Percent Distribution \\
\hline Nitrofurantoin & 12 & 41.37 \\
\hline Nalidixic Acid & 05 & 17.24 \\
\hline Amikacin & 02 & 6.89 \\
\hline Amoxicillin & 02 & 6.89 \\
\hline Norfloxacin & 03 & 10.34 \\
\hline Cefalexin & 04 & 13.79 \\
\hline Gentamycin & 01 & 3.44 \\
\hline Total & 29 & $100 \%$ \\
\hline
\end{tabular}

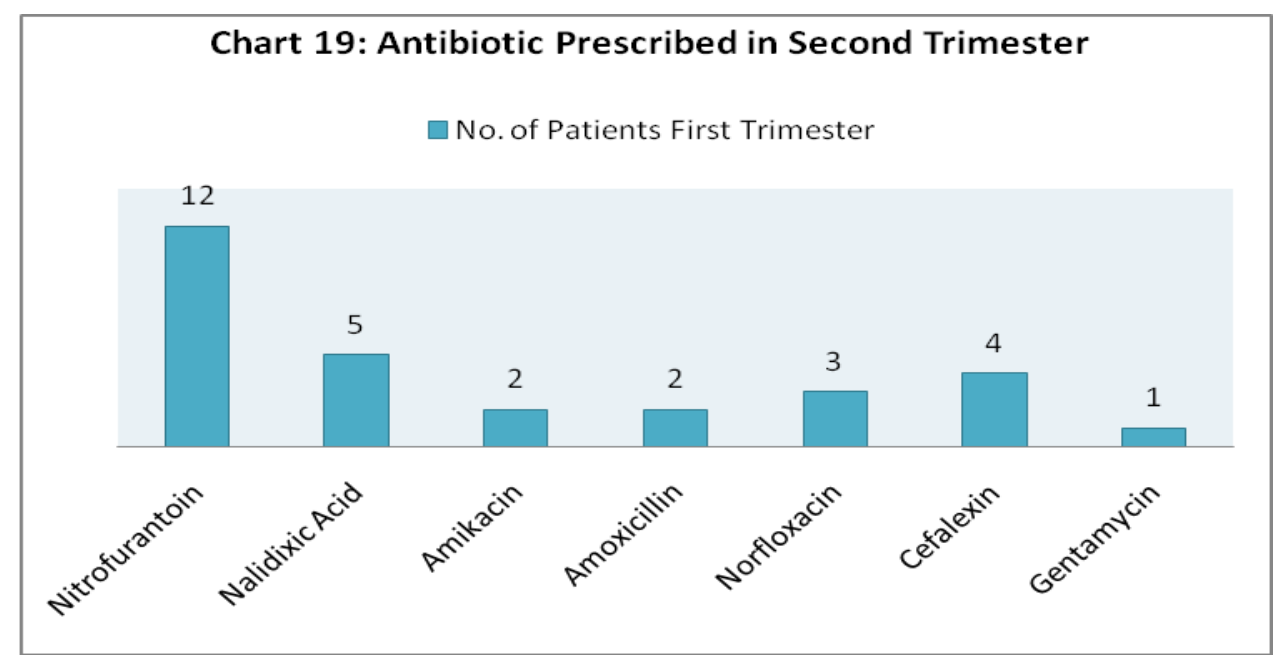

Table 21. Antibiotic Prescription prescribed for Pregnant Female Patients with UTI in Third Trimester as per Antibiotic Sensitivity

\begin{tabular}{|l|l|l|}
\hline Antibiotic Prescribed & No. of Patients Third Trimester & (\%) Percent Distribution \\
\hline Ciprofloxacin & 05 & 55.55 \\
\hline Norfloxacin & 02 & 22.22 \\
\hline Levofloxacin & 02 & $\mathbf{2 2 . 2 2}$ \\
\hline Total & 09 & $\mathbf{1 0 0 \%}$ \\
\hline
\end{tabular}

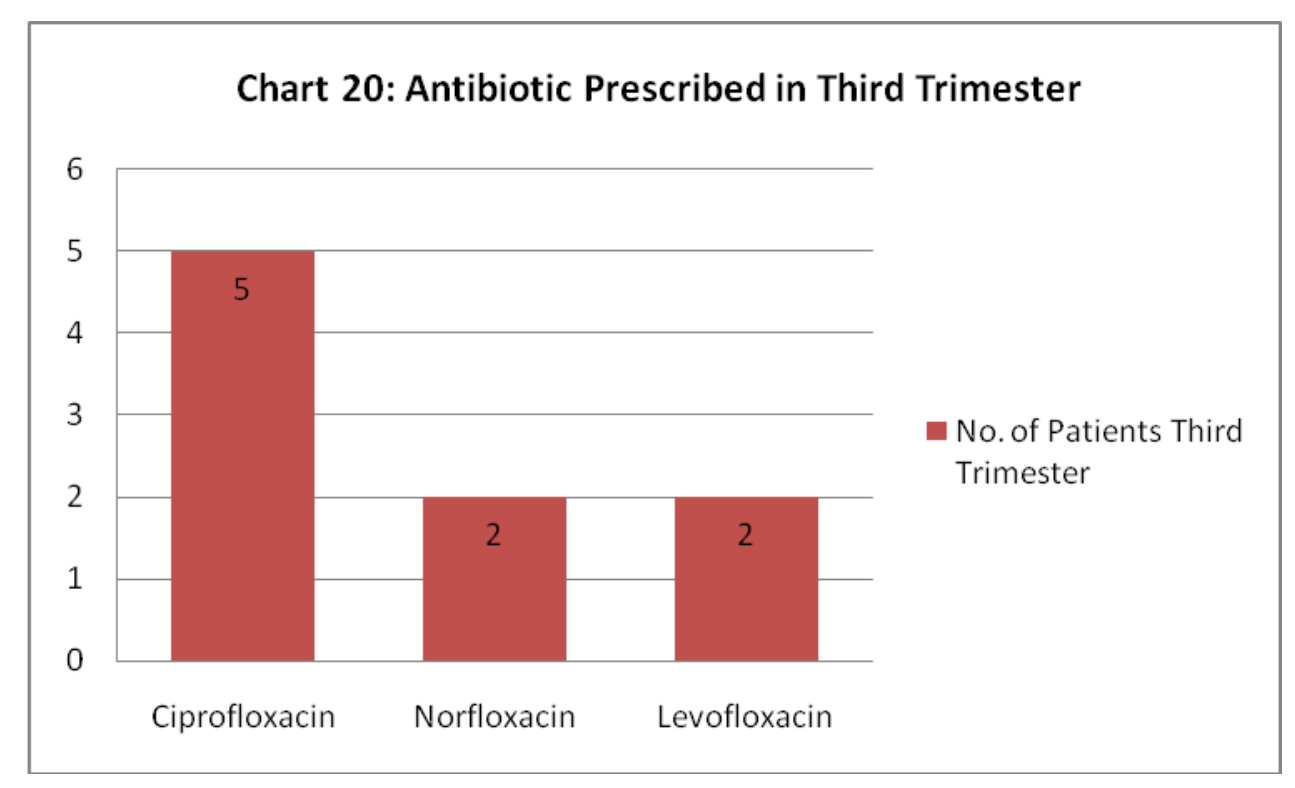


Table 21. Antibiotic Prescription with other drugs prescribed for Pregnant Female Patients with UTI in First Trimester

\begin{tabular}{|l|l|l|}
\hline Antibiotic Prescribed & No. of Patients First Trimester & $(\%)$ Percent Distribution \\
\hline Nitrofurantoin+ Phenazopyridine & 03 & 20 \\
\hline Amoxicillin+ Phenazopyridine+ Methyldopa & 02 & 100 \\
\hline Cotrimoxazole+ Folic Acid & 01 & 100 \\
\hline Nitrofurantoin + Iron+ Folic Acid & 03 & $\mathbf{3 3 . 3 3}$ \\
\hline Nitrofurantoin + Methyldopa & $\mathbf{0 2}$ & $\mathbf{1 3 . 3 3}$ \\
\hline
\end{tabular}

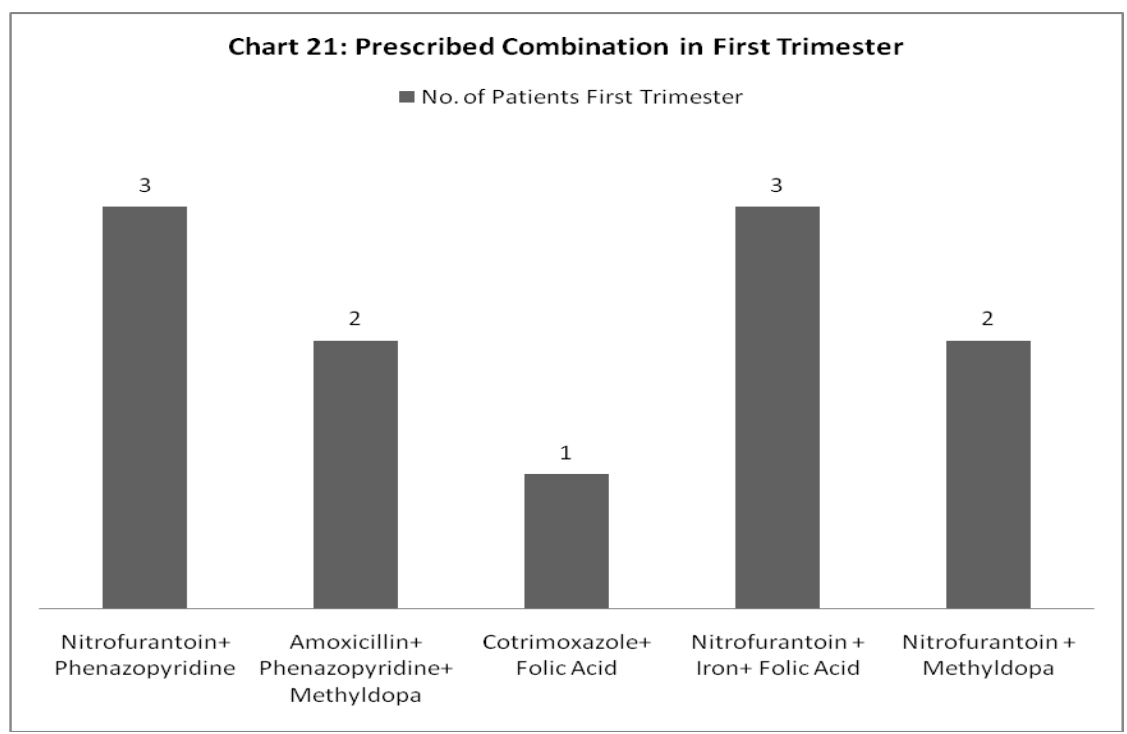

Table 22. Antibiotic Prescription with other drugs prescribed for Pregnant Female Patients with UTI in Second Trimester

\begin{tabular}{|l|l|l|}
\hline Antibiotic Prescribed & No. of Patients Second Trimester & $(\%)$ Percent Distribution \\
\hline Nitrofurantoin+ Phenazopyridine & 09 & $\mathbf{7 5}$ \\
\hline Nalidixic Acid+ Phenazopyridine & 03 & 60 \\
\hline Norfloxacin+ Phenazopyridine & 01 & $\mathbf{3 3 . 3 3}$ \\
\hline Cefalexin+ Phenazopyridine & 01 & 25 \\
\hline Nitrofurantoin+ Folic Acid & 07 & $\mathbf{5 8 . 3 3}$ \\
\hline Nalidixic Acid+ folic Acid & 05 & 40 \\
\hline Cefalexin+ Methyldopa & 01 & 25 \\
\hline Nitrofurantoin+ Glibenclamide & 01 & $\mathbf{0 8 . 3 3}$ \\
\hline
\end{tabular}

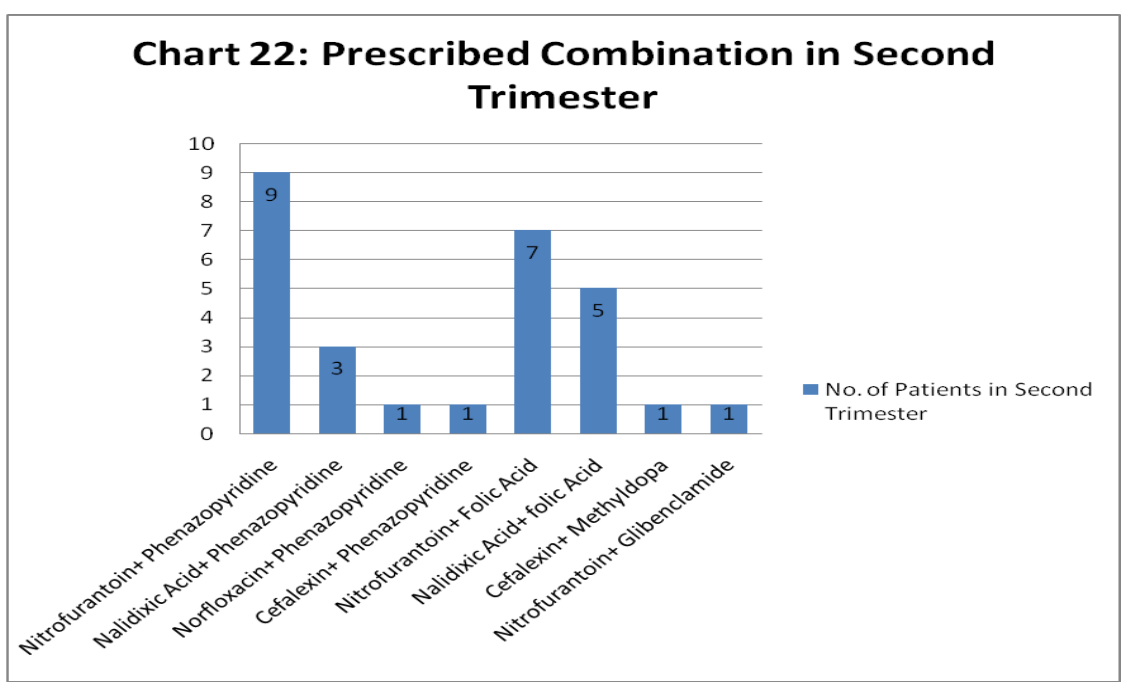


Table 23. Antibiotic Prescription with other drugs prescribed for Pregnant Female Patients with UTI in Third Trimester

\begin{tabular}{|l|l|l|}
\hline Antibiotic Prescribed & No. of Patients Third Trimester & (\%) Percent Distribution \\
\hline Ciprofloxacin+ Folic Acid & 01 & 40 \\
\hline Ciprofloxacin+ Methyldopa & 01 & 20 \\
\hline Norfloxacin+ Folic Acid & 01 & 50 \\
\hline Norfloxacin+ Hydralazine & 01 & 50 \\
\hline Levofloxacin+ Methyldopa & 01 & 50 \\
\hline
\end{tabular}

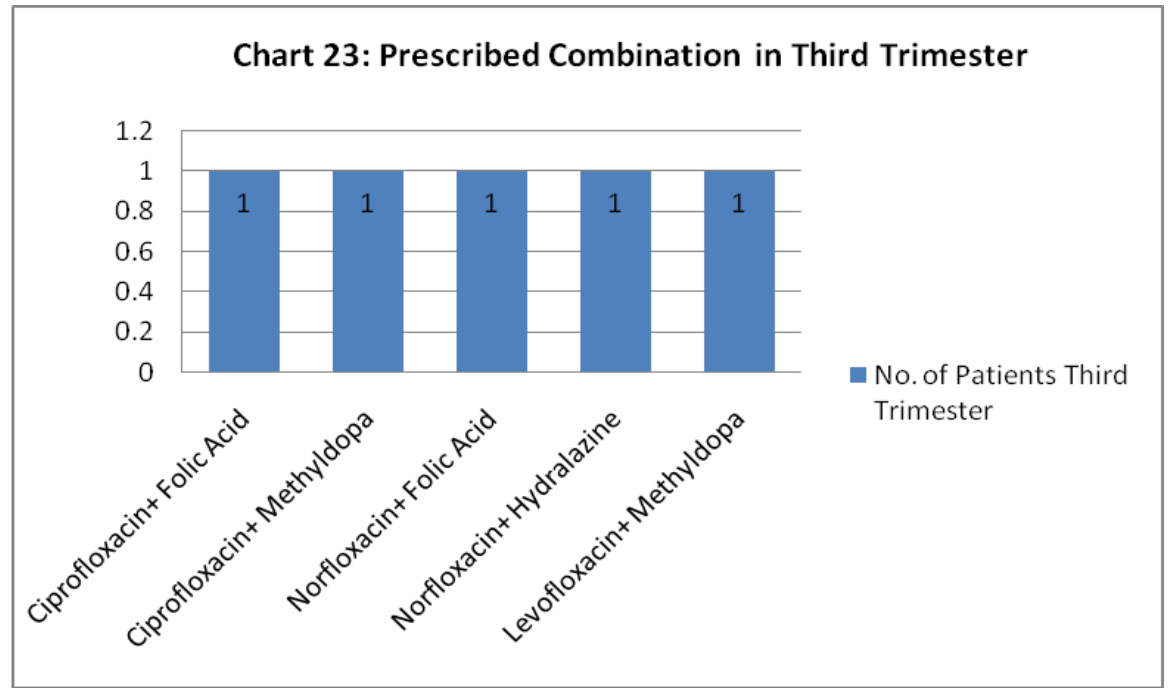

Table 24. Prophylaxis Antibiotic Prescription for UTI Female Pregnant Patients

\begin{tabular}{|l|lc|lccc|}
\hline $\begin{array}{l}\text { Prophylactic } \\
\text { Prescription }\end{array}$ & $\begin{array}{l}\text { No. of } \\
\text { Trimester }\end{array}$ & Patients & $\begin{array}{c}\text { First } \\
\text { To. of } \\
\text { Trimester }\end{array}$ & Patients & $\begin{array}{c}\text { Second No. of Patients } \\
\text { Trimester }\end{array}$ & Third \\
\hline Nitrofurantoin 01 & 02 & 00 & \\
\hline $\begin{array}{l}\text { Methanamine } \\
\text { Hippurate }\end{array}$ & & 02 & 00 & \\
\hline
\end{tabular}

\section{Chart 24:Prophylaxis Antibiotic Prescription for UTI} Female Pregnant Patients

Nitrofurantoin Methamine Hippurate

0

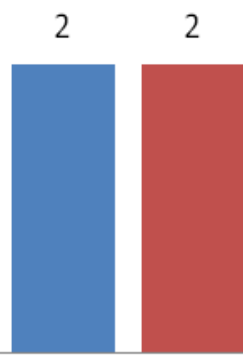

0

0

No. of Patients in First Trimester
No.of Patients in Second Trimester
No. of Patients in Third Trimester 


\section{DISCUSSION}

Discussion of observations is an essential and important part in any scientific clinical research. Discussion is based on the observations and proper analysis. This prospective analysis comprises the prevalence of UTI in 53 pregnant female patients with study of their antibiotic prescription pattern. The findings derived from analysis of variable data are subjected to discussion. Interpretation of the result observed will enable to health care personnel's in formulating the solutions.

Urinary tract infections (UTI's) are one of the most common infections occur during pregnancy. The intent of this study is to determine Rates of prescribed patterns of antibiotics for UTI's in pregnant females according to empirical Guideline for UTI treatments along with any complications raised due to irrational use of antimicrobial Therapy. Different research studies concluded varied incidence of urinary tract infection in pregnant women's. This present prospective study shows that the prevalence rate of urinary tract infection in pregnancy is $26.5 \%$.(53 UTI cases out of screened 200 patients) Controversially, many literature reviewed showed that in pregnant women's UTI incidence can be as high as 8 to $20 \%$.

Present study indicates the incidence of UTI in pregnancy in relation to gestation period shows that max. UTI patients are from second Trimester (55\%) in comparison to first trimester (28\%). Least rate of UTI incidence was in Third trimester $(17 \%)$ due to clinical supervision of pregnant females from starting of gestation.

Observation indicates incidence of UTI in relation to age groups under three gestation periods, max. UTI patients were under age group 21 to 30 years of all gestation periods. In first trimester, Second Trimester and third trimester there were $68 \%, 62 \%$ and $56 \%$ respectively UTI patients were under age group 21-30 years. This prevalence was due to physiological changes that occur majorly in second trimester. Incidence of UTI pregnant patients under age group $<20$ years was more in both $1^{\text {st }}$ and $3^{\text {rd }}$ trimester than under age group $>30$ years. These findings indicate that no relationship exists between age and incidence of UTI in pregnancy.

Incidence of UTI in relation to locality, observation shows, No significant difference in incidence of UTI in between rural and urban locality. Although rural UTI patients were more in number $(55 \%)$ than Urban background. Again patients were more in $2^{\text {nd }}$ trimester than $1^{\text {st }}$ and $3^{\text {rd }}$ trimester. Lower socioeconomic status $(56 \%)$ and lack of proper hygine can be reason of this nearly equal distribution of UTI incidence in rural and urban populations.

Urinary Tract Infections are confirmed on the basis of bacteriuria present. This prospective study supports various reviews for higher rates of occurrence of asymptomatic bacteriuria (No symptoms). The present study indicates that there was max. patients were asymptomatic $(64 \%)$ and from $2^{\text {nd }}$ trimester $(59 \%)$ in comparision to $1^{\text {st }}$ trimester(26\%) and $3^{\text {rd }}$ trimester( $\left.15 \%\right)$. Observations of incidence of symptomatic Bacteriuria showed again $2^{\text {nd }}$ trimester was leading with $47 \%$ incidence rate than $1^{\text {st }}$ and $3^{\text {rd }}$ trimester. This study indicates occurance of UTI was more in $2^{\text {nd }}$ and $1^{\text {st }}$ trimester in comparison to $3^{\text {rd }}$ trimester which can be due to awareness and proper medical supervision near term.

Urinary tract infections are generally uncomplicated in non pregnant females but becomes complicated in pregnancy specially when left untreated. Present study showed incidence of uncomplicated urithritis and cystitis (65\%) and No complicated UTI cases (pyelonephritis). Gestation distribution of uncomplicated UTI patients showed that max. urithritis(38\%) was in

$1^{\text {st }}$ trimester and max. cystitis $(83 \%)$ was in $2^{\text {nd }}$ trimester. Incidence of urithritis in $2^{\text {nd }}$ and $3^{\text {rd }}$ trimester was equal. No cystitis was reported in $3^{\text {rd }}$ trimester. Incidence of recurrent infections was more in $2^{\text {nd }}$ trimester $(80) \%$ than in $1^{\text {st }}$ trimester(20\%). Again $3^{\text {rd }}$ trimester reported zero incidence of recurrent UTI infections.

Present study shows the frequently isolated organism in UTI in pregnancy include species of Enterobacteriaceae especially Escherichia coli and others citrobactor and proteus. Klebsiella was the second (22\%) most isolated organism. Cephalosporin's with more than $90 \%$ general susceptibility than fluoroquinolones $(<90 \%)$. Average general susceptibility was found with Ampicillin and sulphonamides.

Percent distribution of other Comorbid condition indicates that Anaemia and Hypertension was common Comorbid conditions exist in all trimesters. Anaemia was more common in $2^{\text {nd }}$ trimester than $1^{\text {st }}$ trimester. Although Iron and folic acid supplement started early from the beginning of gestation period. Hypertension commonly exists in pregnant females. Hypertension was more common in First trimester and third trimester patients. Only one pregnant female patient in $2^{\text {nd }}$ trimester was found with gestational diabetes. Generally insulin is the DOC for gestational diabetes but in this study we observed OHA Glibenclamide was prescribed for 
treating Diabetes. No thyroid disorder cases reported in all trimesters.

In relation to primary objective of this study, Antibiotic prescription pattern in different gestation periods, this study reveals that Nitrofurantoin was the choice of drug prescribed to treat asymptomatic as well as symptomatic bacteriuria. Although penicillin's, ciphalosporins and fluoroquinolones were also alternative choices. All antibiotic prescription was based on antibiotic sensitivity to culture organism. Present study shows max UTI patients of $1^{\text {st }}$ trimester received Nitrofurantoin (47\%) as a monotherapy. Due to Antibiotic sensitivity to cultural organism, ciphalosporins and fluoroquinolones was also prescribed as monotherapy. Only single UTI pregnant patient shows sensitivity to cotrimoxazole in first trimester. Cotrimoxazole was prescribed with folic acid supplement. As a safe nonteratogenic drug nitrofurantoin was prescribed to max patients with others drugs in combination. Phenazopyridine an urinary analgesic also prescribed in max. number in combination with nitrofurantoin.

Data analysis of observation of $2^{\text {nd }}$ trimester showed that higher percent distribution of patients were received Nitrofurantoin with other drug combinations. Max. no of patients $(75 \%)$ received Nitrofurantoin with phenazopyridine in comparision to other urinary antibiotics. Patients with Vit.B12 deficiency were also receiving Nitofurantoin with folic acid supplement. Only single Hypertensive pregnant received Methyldopa with ciphalosporins. Only single case of gestational diabetes received nitrofurantoin with glibenclamide with safer indication. Nitrofurantoin was again highly prescribed urinary antibiotic drug with other drug combination.

Present study revealed in $3^{\text {rd }}$ trimester fluoroquinolones were better treatment options with other drugs combination. All pregnant female patients with or without Comorbid conditions received fluoroquinolones.

Present study showed that reoccurrence of infection cases was more frequent in pregnant females of Second trimester in comparison to third trimester where no patient reported. This was due to physiological change occurs more promptly in second trimester. Single case was reported in pregnant patient of first trimester. Nitrofurantoin and methanamine hippurate was prescribed in equal distribution as prophylaxis treatment for UTI.

Present study reported rationale use of UTI antibiotics in pregnant female UTI patients which fully supported the primary objective of this study. As this study was a pilot study No adverse effects was reported with antibiotics prescribed in all trimesters as antibiotics were prescribed as per empirical guideline issued by ICMR and other authoritative organizations.

\section{CONCLUSION}

The present prospective, pilot, observational study was performed with the objective to determine rate of antibiotic prescription prescribing as per empirical guidelines. As the irrational prescribing of antibiotics will lead to unnecessary heath problems and increase expenditure for the patients. Prescribing pattern analyzed confirmed that Nitrofurantoin is a relatively inexpensive and safe drug for the treatment of UTI in pregnant female patients. Nitrofurantoin was the highest prescribing drug to treat UTIs in pregnant female patients. Cephalosporin and Quinolones were the second most commonly used drugs for the treatment of UTI. Fluroquinolones was not considered as first line therapy due to proneness to microbial resistance. According to this study antibiotics prescribed was as per empirical guideline. This study has shown that the prevalence of urinary tract infection during pregnancy is $26.5 \%$ and E.coli is the most common causative agents of UTI in pregnancy.

Data created and analyzed under this present study serves as a frame work for further studies to investigate the scope for educational intervention, action plan generation and improvement in prescribing patterns so as to improve the quality of patient care. Comparing the current prescribing pattern of antibiotics with the standard treatment/ prescription guidelines will enhance the effectiveness of treatment.

\section{REFERENCES}

1. Urinary tract infections, viewed 25 March 2020.< https://www.mayoclinic.org/diseasesconditions/urinary-tract-infection/symptomscauses/syc-20353447>

2. James McIntosh 2010, What to know about urinary tract infections, Medical News Today. Viewed $25 \quad$ March 2020.< https://www.medicalnewstoday.com/articles/1 89953>

3. Jancel,T \& Dudas,V2002,'Management of uncomplicated urinary tract infections', West J Med, vol 176,pp.51-55

4. Kant,s, Lohiya,A, Kapil,A, Gupta,SK 2017,'Urinary tract infections among pregnant women at a secondary level hospitals in northern india', Indian Journal of Public Health, vol.61, no.2, pp. 118-123 
5. Lee et al.2020,' Urinary tract infections in pregnancy in a rural population of Bangladesh: Population based prevalence, risk factors, etiology and antibiotic resistance', BMC Pregnancy and child, (2020) 20:1, pp.1-11, https://doi.org/10.1186/s12884-019-2665-0

6. Patricia,JH, Robert, PG 2019,'Urinary Tract Infections in Pregnancy', StatPearls Publishing, NCBI Bookshelf. A service of the National Library of Medicine, National Institutes of Health. Viewed 30 March< https://www.ncbi.nlm.nih.gov/books/NBK537 047/>

7. Ramnath, KV, shafiya, SB 2011,'prescription pattern of antibiotic usage for urinary tract infection treated in a rural tertiary care hospital', Indian Journal of Pharmacy Practice, vol. 4, no.2, pp. 57-63

8. Raisa O Platte 2019, Urinary Tract Infections in Pregnancy, Medscape. Viewed 30 March 2020.<

https://emedicine.medscape.com/article/4526 04-overview\#a1>

9. Joanna, MR, Jolanta, M, Monika W 2013,'Urinary tract infections in pregnancy: old and new unresolved diagnostic and therapeutic problems', Arch Med Sci 2015, vol. 11, no. 1, pp. 67-77, DOI: 10.5114/aoms.2013.39202

10. Thomas, MH, Gupta, K2020,' Urinary tract infections and asymptomatic bacteriuria in pregnancy, UpToDate, viewed 03 April $2020 .<$

https://www.uptodate.com/contents/urinarytract-infections-and-asymptomatic-

bacteriuria-in-pregnancy>

11. Christine DiMaria, Matthew Solan and Ana Gotter 2018, asymptomatic bacteriuria, healthline, viewed 03 April 2020.< https://www.healthline.com/health/pregnancy/ infections-asymptomatic-bacteriuria

12. Imade et al.2010,' Asymptomatic bacteriuria among pregnant women', N Am J Med Sci. 2010, vol. Jun; 2(6), pp. 263-266, doi: 10.4297/najms.2010.2263:

10.4297/najms.2010.2263

13. Najar, MS, Saldanha, CL, Banday AK 2009,' Approach to Urinary Tract Infections', Indian J Nephrol, vol. Oct;19(4), pp.129-39.doi: 10.4103/0971-4065.59333.

14. Loh, KY, Sivalingam, N,'Urinary tract infections in pregnancy', Malaysian Family Physician. Vol. 2007;2(2), pp. 54-57

15. Nowicki, B, Sledzinska, A, Samet, A, Nowicki, S2010,' Pathogenesis of gestational urinary tract infection: urinary obstruction versus immune adaptation and microbial virulence. BJOG 2011, vol.118, pp.109-112.

16. Delzell, JE, Lefevre, ML2000,'Urinary Tract Infections during Pregnancy',Am Fam Physician, vol. 2000 Feb1;61(3), pp.713-720

17. Managing urinary tract infections in pregnancy, viewed 03 April 2020.< https://bpac.org.nz/BPJ/2011/april/pregnantuti.aspx>

18. Patrick, D2018,'Which antibiotics should be used with caution in pregnant women with UTI?', OBG Management, vol.30, no.3, pp.14-17

19. ICMR (2019), Treatment guidelines for antimicrobial use in common syndromes, $2^{\text {nd }}$ edition, ICMR publications, viewed 29 May 2020.

http://www.ijmm.org/documents/Treatment_ Guidelines_2019_Final.pdf>

20. Shelat,PR, kalakaPPa, SP2015,'Analysis of outdoor patients prescription according to world health organization (WHO) prescribing indicators among private hospitals in wertern india', Journal of Clinical and Doagnostic Research, vol.9(3), pp.1-5

21. S. Shanmugapriya, S, Saravanan, T, Venkatrajan, R, Thomas PM2018,' Drug prescription pattern of outpatients in a tertiary care teaching hospital in Tamil Nadu', Perspect Clin Res. 2018 Jul-Sep, vol.9(3), pp.133-138. doi: 10.4103/picr.PICR_86_17: 10.4103/picr.PICR_86_1 